\title{
Riboflavin as an Oral Tracer for Monitoring Compliance in Clinical Research
}

\author{
V.M. Sadagopa Ramanujam*, Karl E. Anderson, James J. Grady, Fatima Nayeem and \\ Lee-Jane W. Lu
}

Department of Preventive Medicine and Community Health, the University of Texas Medical Branch, Galveston, TX 77555-1109, USA

\begin{abstract}
We studied urinary riboflavin as an objective biomarker of compliance in clinical research using a simplified method amenable to high throughput analysis. Six healthy women not taking vitamin supplements ingested a study pill containing riboflavin $(32 \mathrm{mg})$ as an inactive tracer and the soy isoflavones daidzin $(0.243 \mathrm{mmole})$ and genistin $(0.222$ mmole) as active ingredients once daily for four days. Riboflavin and metabolites of the isoflavones were measured in urine samples obtained before and after each pill. Urinary excretion of riboflavin and metabolites of both isoflavones peaked within $8 \mathrm{hrs}$ and remained higher than baseline for $24 \mathrm{hrs}$. Urinary excretion of riboflavin was also measured in 152 additional women with unrestricted dietary supplement intakes. Mean and median urinary riboflavin concentrations in these women were 0.42 and $0.31 \mu \mathrm{g} / \mathrm{mL}$, respectively, compared to $0.2 \mu \mathrm{g} / \mathrm{mL}$ during a riboflavin-restricted diet. Receiver operating characteristics (ROC) curves indicated that urinary riboflavin within 24 hrs after a $32 \mathrm{mg}$ dose would perform well as a measure of compliance (all areas under the ROC curves $\geq 0.84$. Samples collected during the initial 8 hrs after pill ingestion performed better as a compliance measure than later collections. In summary, compliance in a clinical study can be monitored in real time by incorporating $32 \mathrm{mg}$ of riboflavin into study pills, with compliance indicated by urinary riboflavin levels increasing over individual baselines or to $\geq 1.0 \mu \mathrm{g} / \mathrm{mL}$, with a false positive rate of being classified as compliant at $<5 \%$.
\end{abstract}

Keywords: biomarker, compliance monitoring, clinical trial, riboflavin.

\section{INTRODUCTION}

Compliance assessment is important for ensuring success in clinical trials. Methods for monitoring compliance include patient diaries, patient self-reports, pill counts at the time of study visits, and measurement of a treatment ingredient or a tracer substance in blood or urine $[1,2]$. Compliance is generally more accurately assessed by urine and blood measurements than by self reporting [2]. Measurement of a treatment ingredient can be analytically challenging for many test substances (e.g. antibody-based therapies, compounds with short half-lives, substances in a placebo etc.). Addition of a low toxicity compound that is easily measured in biological fluids is an attractive alternative to assess compliance for medication ingestion.

Riboflavin (vitamin $\mathrm{B}_{2}$ ) is an attractive marker for compliance because it is rapidly absorbed and excreted, does not accumulate in the body, and has negligible toxic effects when fed to humans even at fairly high doses [3]. The recommended daily allowance of riboflavin is $1.7 \mathrm{mg}$ for adults and $2.0 \mathrm{mg}$ for pregnant and lactating women [4]. Even amounts of riboflavin approaching $400 \mathrm{mg} /$ day for three months in a migraine prophylaxis study ( $\mathrm{N}=55$ subjects) were associated only with some cutaneous side effects (e.g.

*Address correspondence to this author at the Department of Preventive Medicine and Community Health, the University of Texas Medical Branch, 700 Harborside Drive, Galveston, TX 77555-1109, USA; Tel: (409) 7724661; Fax: (409) 772-6287; E-mail: sramanuj@utmb.edu itching, burning, pricking, and numbness) and yellow discoloration of the urine [3].

In some clinical trials, riboflavin was used as an adherence marker and detected in urine by visual fluorescence under UV illumination [5-7] or by fluorescence spectrophotometry [8-11]. When $30-50 \mathrm{mg}$ of riboflavin was given by mouth, fluorescence was visible in only $60-70 \%$ of urine samples collected at 13-24 hours [5-7]. With 25-50 mg riboflavin, a fluorescence spectrophotometry method that involved a 2-3 step phenol extraction detected riboflavin at a concentration of $\geq 1.5 \mu \mathrm{g} / \mathrm{mL}$, which was considered positive for compliance, in $85-95 \%$ of $24 \mathrm{hr}$ urine collections [8-11]. However, it is not clear how this proposed cut-off value compares with levels seen with usual diets and nutritional supplement ingestion.

A previous study that measured urinary riboflavin after single doses between 5 and $100 \mathrm{mg}$ indicates that maximum absorption occurs with doses between 20 and $50 \mathrm{mg}$ [12]. In a study to assess biological effects of soy isoflavones in healthy females, we incorporated $32 \mathrm{mg}$ of riboflavin into the study pills, both active treatment and placebo. In a substudy reported here, we attempted to define the concentrations of riboflavin in urine that indicate compliance with study pill ingestion. Urinary excretion of riboflavin and the two soy isoflavones were measured in six women not participating in the main clinical trial, and compared with riboflavin excretion in 152 women on no dietary supplement restrictions and not taking study pills. The analytical method 
was suitable for rapidly assessing compliance and potentially for high throughput analysis.

\section{STUDY DESIGN AND METHODS}

\section{Study Design}

Study subjects $(n=6)$ were apparently healthy 30 to 40 year old pre-menopausal women from Galveston, Texas and surrounding communities, who were not pregnant, breastfeeding, or taking contraceptive medications. They were screened for an outpatient study on the effects of soy isoflavones on markers of breast cancer risk, but instead participated in this sub-study to assess the use of riboflavin incorporated into a study pill as a compliance marker when ingestion of nutritional supplements is restricted. In a separate but comparable group of 152 women who were not restricted as to diet or ingestion of supplements, excretion of riboflavin derived from their usual diets and nutritional supplements was assessed by measuring riboflavin in three or four $12-\mathrm{hr}$ overnight urine collections. The study site was the General Clinical Research Center (GCRC) at the University of Texas Medical Branch (UTMB). The study was approved by the Institutional Review Board at UTMB, and written informed consent was obtained from all subjects.

The six subjects were instructed to avoid riboflavin from other sources, ingested one study pill daily for 4 days as directly observed by the nursing staff of the GCRC, and then collected all urine at timed intervals for up to $24 \mathrm{hrs}$ after each pill. The study pills contained $32 \mathrm{mg}$ of riboflavin, 0.243 mmole of daidzin, and 0.222 mmole of genistin and were prepared specifically for this study by Archer Daniel Midland Co., Decatur, IL. Urine was collected for $12 \mathrm{hrs}$ at home the night before and for $2 \mathrm{hrs}$ just before ingestion of the first study pill. After ingestion of first study pill, urine voids were pooled every two hours for the first $8 \mathrm{hrs}$ (to obtain a more detailed picture of riboflavin excretion pattern), the next $14 \mathrm{hrs}$, and the final $2 \mathrm{hrs}$ before the ingestion of next pill. After pill 2, 3, and 4, urine voids were pooled for the first $8 \mathrm{hrs}$, the next $14 \mathrm{hrs}$, and last $2 \mathrm{hrs}$ post-ingestion, respectively.

In the 152 women not restricted as to their usual diets or ingestion of supplements, excretion of riboflavin was assessed by measuring riboflavin in three or four 12-hr overnight urine collections. For both groups, urine was collected at room temperature in light-proof bottles containing 1 gram of ascorbic acid, and aliquots were stored at $-20^{\circ} \mathrm{C}$ and thawed immediately before analysis.

\section{Analysis of Riboflavin by HPLC with Fluorescence De- tection}

The method of Gatautis and Naito [13], which can separate riboflavin from other fluorescence endogenous substances (e.g. flavin mononucleotide, flavin-adenine dinucleotide, and lumiflavin), was modified to include centrifugation at room temperature to remove any solid material that might obstruct HPLC column flow. Solvent blanks run past the elution time of riboflavin showed no fluorescence emission peaks at wavelengths near that for riboflavin. Aliquots of $100 \mu \mathrm{L}$ were diluted 2 to 40 times with purified water such that at least two dilutions were within the linear concentration range for the assay, thus allowing accurate measurement over a wide range of riboflavin concentrations $[13,14]$. The analysis was carried out using a Perkin-Elmer Model 200 HPLC system equipped with a binary gradient LC pump for mixing two solvents, a fluorescence detector, a UV detector, a reversed phase $\mathrm{C}-18$ Bondclone 10 micron column (Phenomenex Inc., Torrance, CA) with an isocratic aqueous methanol solution (methanol/water, 1:2, v/v) for elution at a flow rate of $1 \mathrm{~mL} / \mathrm{min}$, and Perkin-Elmer TotalChrom 630 software for data acquisition and analysis. For fluorescence detection, the excitation and emission wavelengths were set at $450 \mathrm{~nm}$ and $530 \mathrm{~nm}$, respectively. Each diluted urine sample was analyzed in duplicate, and the mean peak area used for calculating riboflavin concentrations.

\section{Analysis of Daidzein and Genistein by Gas Chromatog- raphy-Flame Ionization Detection (GC-FID)}

Daidzein and genistein, which are metabolites of daidzin and genistin, respectively, were analyzed by a GC-FID, as described previously [15]. Briefly, $15 \mathrm{~mL}$ of urine was mixed with sodium acetate solution $(0.3 \mathrm{~mL}, 2.0 \mathrm{M}, \mathrm{pH} 5)$, $\beta$-glucuronidase $(0.2 \mathrm{~mL}, 11,400$ units, Sigma Chemical Co., St. Louis, MO) and an internal standard, 7,4'dihydroxyflavone $(200 \mu \mathrm{g})$, and incubated for $24 \mathrm{hrs}$ at $37^{\circ} \mathrm{C}$ to hydrolyze the glucuronide and sulfate conjugates of daidzein and genistein. The $\mathrm{pH}$ was adjusted to 7.0 with solid ammonium carbonate, and unconjugated daidzein and genistein were adsorbed onto a $50 \mathrm{~mL}$ ChemElut ${ }^{\mathbb{B}}$ column (Analytichem International, Harbor City, CA) directly, and eluted 3 times with $15 \mathrm{~mL}$ ethyl acetate. An aliquot of this eluate was dried and silylated using $50 \% \quad \mathrm{~N}, \mathrm{O}-$ bis(trimethylsilyl)-trifluoroacetamide containing $\quad 1 \%$ trimethylchlorosilane (Pierce, Rockford, Il) in pyridine for 2 hrs at $90^{\circ} \mathrm{C}$. The silylated derivatives were separated by GC (Hewlett Packard 5890A, Palo Alto, CA) using a megabore HP-1 column ( $30 \mathrm{~m} \times 0.538 \mathrm{~mm}$ i.d. x $0.88 \mathrm{~mm}$ film thickness), with nitrogen as carrier gas, injector and detector temperatures of $275^{\circ} \mathrm{C}$ and $350^{\circ} \mathrm{C}$, respectively, and a column flow rate of $20 \mathrm{~mL} / \mathrm{min}$. Oven temperature was $85^{\circ} \mathrm{C}$ for 4 min and then programmed to increase to $275^{\circ} \mathrm{C}$ at a rate of $30^{\circ} \mathrm{C} / \mathrm{min}$.

\section{Statistical Analysis}

Urinary riboflavin, daidzein, and genistein are expressed both as concentrations $(\mu \mathrm{g} / \mathrm{mL})$ and as excretion rates $(\mu \mathrm{g} / \mathrm{hr})$, and data are presented as means and medians, standard deviations (SD) and 95\% confidence intervals (95\% CI) of the means. The hourly excretion rates of riboflavin $(\mu \mathrm{g} / \mathrm{hr})$ at various timed intervals and \%recoveries of the daily intake were compared among the four pills by repeated measures ANOVA and with baseline levels in six subjects by paired ttest. A $P$ value $\leq 0.05$ was considered statistically significant.

The results in these six subjects, who took the study pill under direct supervision, were considered true positive for estimating sensitivity of the compliance test. The results from the 152 subjects not taking the study pill were considered true negative for estimating specificity of the compliance test, since they did not take the study pill but were exposed to riboflavin from their unrestricted diets and nutritional supplements. Receiver operating characteristic (ROC) curves were generated [16].

To generate ROC curves, riboflavin levels in the entire study samples were ranked and all values between low to 
high were used as hypothetical cut-offs. For each hypothetical cut-off level studied, true and false negative rates of noncompliance were estimated in the group of 152 subjects, and true and false positive rates of compliance were estimated in the six subjects who ingested the riboflavin-containing study pill. The specificity and sensitivity for every level of riboflavin as a cut-off for projecting compliance were calculated and used to construct ROC curves using SigmaPlot ${ }^{\circledR} 11$ for Windows (Systat Software Inc., San Jose, CA). ROC curves were constructed separately for riboflavin expressed as excretion rate $(\mu \mathrm{g} / \mathrm{hr})$ and concentration $(\mu \mathrm{g} / \mathrm{mL})$ and for urine samples collected over the initial $8 \mathrm{hr}$ post pill ingestion and for samples collected between 8 and $24 \mathrm{hrs}$ post pill ingestion. Area under the curve (AUC) was calculated for various ROC curves as summary statistics using SigmaPlot ${ }^{\circledR}$. Statistical analyses were performed using $\operatorname{SAS}^{\circledR}$ (Version 9.1., SAS Institute, Inc. Cary, NC).

\section{RESULTS}

The modified HPLC-fluorescence method described by Gatautis and Naito [13] required little sample preparation and was amenable to rapid throughput. Solvent blanks showed no fluorescence emission peaks at wavelengths near that for riboflavin. With dilution of urine samples 2 to 40 times, measured riboflavin concentrations were linear and accurate over a concentration range 0.01 to $2 \mu \mathrm{g} / \mathrm{mL}$. For example, at a measured concentration of $0.01 \mu \mathrm{g} / \mathrm{mL}$, a riboflavin standard gave a fluorescence peak signal of 10,000 \pm $500 \mu \mathrm{V}$ (mean $\pm \mathrm{SD}$ ). A concentration of $0.005 \mu \mathrm{g} / \mathrm{mL}$ riboflavin in a diluted urine sample gave a peak area signal of only $\sim 5,000 \pm 1500 \mu \mathrm{V}$, which was detectable but with a high (up to $30 \%$ ) coefficient of variation (CV). After repeated freezing and thawing of urine samples stored in lightproof bottles over 2 months, riboflavin concentrations were $85 \%$ to $95 \%$ of those measured in freshly prepared samples (data not shown).

Excretion rates of riboflavin, daidzein, and genistein in urine collected $0-8,8-22$, and 22-24 hrs after pill ingestion were assessed in the group of six women and expressed in $\mathrm{mg} / \mathrm{hr}$, as shown in Fig. (1). In all 6 subjects, urinary excretion of all three compounds was maximal within the first 8 hrs after ingestion of each of the four study pills. Riboflavin excretion between 0-8 hrs (pooled from four 2-hr fractions for graphing purpose) appeared to be higher after first pill compared to those from the other 3 doses (a single $8-\mathrm{hr}$ pooled fraction). However, these differences, including 8-22 and 22-24 hr interval collections, were not statistically significant for riboflavin, daidzein, or genistein excretion (Fig. 1, all $\mathrm{P}>0.05$ ). Mean $24 \mathrm{hr}$ recoveries of riboflavin, daidzein, and genistein among subjects are shown in Table 1. Recoveries of riboflavin and daidzein in urine as percent of daily intakes were not significantly different after each of the four pills $(P>0.05$, Table 1), which is consistent with excretion rates shown in Fig. (1). However, total intake recoveries for genistein differed significantly by repeated measures ANOVA (Table 1). Recoveries of riboflavin in this study are consistent with prior reports [17-21]. The excretion patterns of daidzein and genistein shown in Fig. $(\mathbf{1 B}, \mathbf{C})$ are consistent with findings from our previous studies [15]. Urinary excretions $(\mu \mathrm{g} / \mathrm{hr})$ of riboflavin, daidzein, and genistein at all time points up to $24 \mathrm{hrs}$ after each pill, including the 22-24 hr time interval, were all greater (5-10 fold) than at baseline ( $P$ values $\leq 0.05$ by paired t-test).

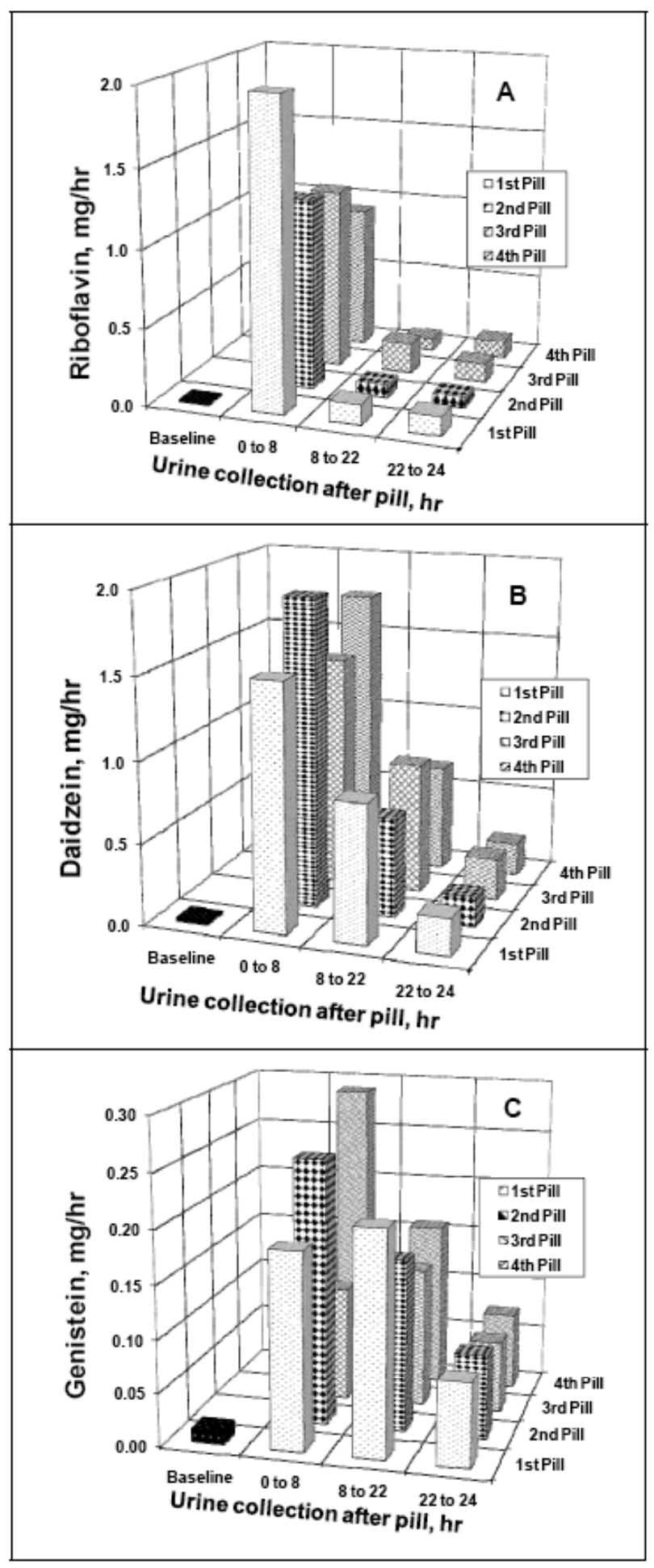

Fig. (1). Mean urinary excretion rates, $\mathrm{mg} / \mathrm{hr}$, (z-axis) of riboflavin (A), daidzein (B), and genistein (C) after ingesting each of the four study pills ( $y$-axis). Urine collected during baseline and at timed intervals after pill ingestion is shown on the $x$-axis. Each subject $(\mathrm{n}=6)$ ingested a total of $32 \mathrm{mg}$ riboflavin, $0.243 \mathrm{mmole}$ of daidzin, and 0.222 mmole of genistin once every day for four days. Comparisons among each time point of an analyte after four different daily doses by repeated measures ANOVA showed no difference (all $P>0.05$ ). 
Table 1. Daily Intake Recoveries in Urine of 6 Women After a Daily Dose of Riboflavin (32 mg), Daidzin (0.243 mmole), and Genistin (0.222 mmole) for Four Days

\begin{tabular}{|c|c|c|c|c|}
\hline \multirow{2}{*}{ Metabolite } & \multicolumn{4}{|c|}{ \%-Daily intake recovered in urines (mean \pm SD)* } \\
\cline { 2 - 5 } & Pill 1/Day 1 & Pill 2/Day 2 & Pill 3/Day 3 & Pill 4/Day 4 \\
\hline \hline Riboflavin & $55.5 \pm 24.5$ & $36.1 \pm 24.3$ & $40.0 \pm 24.6$ & $28.0 \pm 19.2$ \\
\hline Daidzein & $36.6 \pm 20.1$ & $39.1 \pm 22.7$ & $38.3 \pm 22.1$ & $39.0 \pm 21.8$ \\
\hline Genistein** & $6.9 \pm 3.8$ & $7.3 \pm 4.2$ & $4.8 \pm 2.3$ & $7.9 \pm 4.4$ \\
\hline
\end{tabular}

* Comparison by analyte among four different daily doses by repeated measures ANOVA.

**Test of equal means rejected only for genistein $(\mathrm{P}=0.01)$, but not for riboflavin or daidzein.

Results of statistical analyses of the data for urinary riboflavin excretion rates $(\mu \mathrm{g} / \mathrm{hr})$ and concentrations $(\mu \mathrm{g} / \mathrm{mL})$ at all time points are provided in Table 2. Excretion rates of riboflavin (expressed as $\mathrm{mg} / \mathrm{hr}$ in Fig. (1) and $\mu \mathrm{g} / \mathrm{hr}$ in Table 2) and daidzein (Fig. 1) in all urine samples within $24 \mathrm{hrs}$ including the 22-24 hr interval were more than $2 \mathrm{SD}$ above baseline values. However, genistein concentrations exceeded baseline by $>2$ SD in only 18 of the 23 samples collected 2224 hours after pill ingestion. Therefore, riboflavin excretion had a stronger correlation with daidzein $(\mathrm{r}=0.74, P<0.001)$ than with genistein excretion $(\mathrm{r}=0.59, P=0.003)$, and riboflavin and daidzein were better markers than genistein for assessing compliance.

Each of the 152 women who did not take study pills and were not instructed to modify diets or intakes of supplements provided 3 to 4 urine samples on different days, for a total of 584 samples. As shown in Table 2, urinary concentrations of riboflavin were on average 3-4 times higher than the baseline concentrations of the six study subjects who were instructed to avoid all vitamin supplementation. There were large within- and between-subject variations in urinary excretion of riboflavin among the group of 152 women, with withinsubject CVs (3-4 samples per subject) ranging from 5\% to $165 \%$, and between-subject CVs $(n=152)$ ranging from $19 \%$ to $1,234 \%$ for excretion rates $(\mu \mathrm{g} / \mathrm{hr})$. Corresponding withinand between-subject $\mathrm{CVs}$ for riboflavin concentrations $(\mu \mathrm{g} / \mathrm{mL})$ in urine ranged from 9 to $149 \%$ and 15 to $2,361 \%$, respectively. None of these 152 subjects had riboflavin concentrations exceeding the mean urinary concentration of 2.3 $\mu \mathrm{g} / \mathrm{mL}$ found in the 6 study subjects at $22-24 \mathrm{hrs}$ after ingesting the study pill containing riboflavin.

To assess the performance of riboflavin as a compliance marker, ROC curves were constructed using results expressed as both excretion rates and concentrations, with data

Table 2. Urinary Excretion $(\mu \mathrm{g} / \mathrm{hr})$ and Concentrations $(\mu \mathrm{g} / \mathrm{mL})$ of Riboflavin in 6 Women on Restricted Dietary Supplements Taking Study Pills Containing $32 \mathrm{mg}$ of Riboflavin Once Daily for Four Days and in 152 Women with Unrestricted Dietary Supplements not Taking the Study Riboflavin Pill

\begin{tabular}{|c|c|c|c|c|c|c|c|}
\hline Riboflavin levels & $\begin{array}{l}\text { Total urine } \\
\text { samples }^{\mathrm{a}}\end{array}$ & Mean $^{b}$ & SD & $95 \% \mathrm{CI}$ & Median & Minimum & Maximum \\
\hline \multicolumn{8}{|c|}{ Riboflavin excretion $(\mu \mathrm{g} / \mathrm{hr})$} \\
\hline Baseline, before riboflavin & 12 & 7.5 & 3.6 & $3.7,11.3$ & 6.3 & 3.6 & 13.5 \\
\hline 0-8 $\mathrm{hr}$ after riboflavin & 42 & 1611 & 1756 & 1063,2158 & 1254 & 186.4 & 9488 \\
\hline $\begin{array}{l}22-24 \mathrm{hr} \text { after riboflavin } \\
\text { Subjects not taking riboflavin }(\mathrm{n}=1\end{array}$ & $23^{\mathrm{d}}$ & 103.5 & 79.8 & $68.9,137.9$ & 90.8 & 15.1 & 304.1 \\
\hline $12 \mathrm{hr}$ collection, 3 to 4 times & 584 & 32.4 & 32.9 & $27.1,37.7$ & 22.9 & 1.4 & 214.4 \\
\hline \multicolumn{8}{|c|}{ Riboflavin concentration $(\mu \mathrm{g} / \mathrm{mL})$} \\
\hline $8-22 \mathrm{hr}$ after riboflavin & $28^{\mathrm{c}}$ & 2.9 & 2.3 & $2.0,3.7$ & 2.1 & 0.4 & 7.3 \\
\hline $22-24 \mathrm{hr}$ after riboflavin & $23^{\mathrm{d}}$ & 2.3 & 1.7 & $1.6,3.1$ & 1.9 & 0.5 & 7.5 \\
\hline \multicolumn{8}{|l|}{ Subjects not taking riboflavin $(\mathrm{n}=152)$} \\
\hline $12 \mathrm{hr}$ collection, 3 to 4 times & 584 & 0.4 & 0.3 & $0.4,0.5$ & 0.3 & 0.1 & 1.7 \\
\hline
\end{tabular}

${ }^{\text {a } H o u r s ~ a n d ~ f r a c t i o n s ~ o f ~ c o l l e c t i o n s ~ v a r i e d ~ f r o m ~ p i l l ~ t o ~ p i l l ~(c o n s u l t ~ t e x t ~ f o r ~ m o r e ~ d e t a i l s) . ~}$

${ }^{\mathrm{b}}$ Compared with baseline by paired t-test (all $\mathrm{p} \leq 0.05$ ).

${ }^{\mathrm{c}}$ Two subjects missed one collection.

${ }^{\mathrm{d}}$ One subject missed one collection. 
from the six subjects defined as truly compliant and from the 152 subjects as truly noncompliant for this analysis. A method for monitoring compliance is most effective in clinical trials if it can detect a compliance tracer in urine samples collected at various timed intervals after pill ingestion. Therefore, we used riboflavin levels from all timed urine collections including samples collected on study site for assessing sensitivity and specificity. Fig. (2) shows that riboflavin performed well for measuring compliance, because the AUCs for all ROC curves (0-8 hours and 8-24 hours, and for results expressed either as excretion rate or concentration) were all $>0.5$, i.e. above the 45 degree line, a line representing results that would be obtained by chance. The ROC curves (Fig. 2) appeared to predict compliance better, as expected, for urine collected within the first $8-\mathrm{hr}(\mathrm{AUC}=0.99$ and 1.00) than between 8 to 24-hr after pill ingestion (AUC $=0.84$ and 0.94 , all $\mathrm{P}$ values $<0.01$ by pair-wise comparison), reflecting higher levels in the earlier samples, and for results expressed as concentrations compared to excretion rate. Using $1 \mu \mathrm{g} / \mathrm{mL}$ or $100 \mu \mathrm{g} / \mathrm{hr}$ as thresholds for assessing compliance for urine collected $>8 \mathrm{hrs}$ post-pill ingestion, positive likelihood ratios for concentration and excretion measurements were 12.1 and 8.2, respectively; and negative likelihood ratios were 0.29 and 0.62 , respectively. Sensitivity and specificity for $1 \mu \mathrm{g} / \mathrm{mL}$ (concentration) were 0.72 and 0.94 , respectively; and sensitivity and specificity for 100 $\mu \mathrm{g} / \mathrm{hr}$ (excretion rate) were 0.41 and 0.95 , respectively. Spot urine samples collected 22-24 hrs after pill ingestion had riboflavin concentrations $>1 \mu \mathrm{g} / \mathrm{mL}$. Therefore, a urine concentration $>1 \mu \mathrm{g} / \mathrm{ml}$ is a reasonable cutoff for identifying compliance in taking a pill containing $32 \mathrm{mg}$ of riboflavin within the past $24 \mathrm{hrs}$, with a type I misclassification error of $<5 \%$.

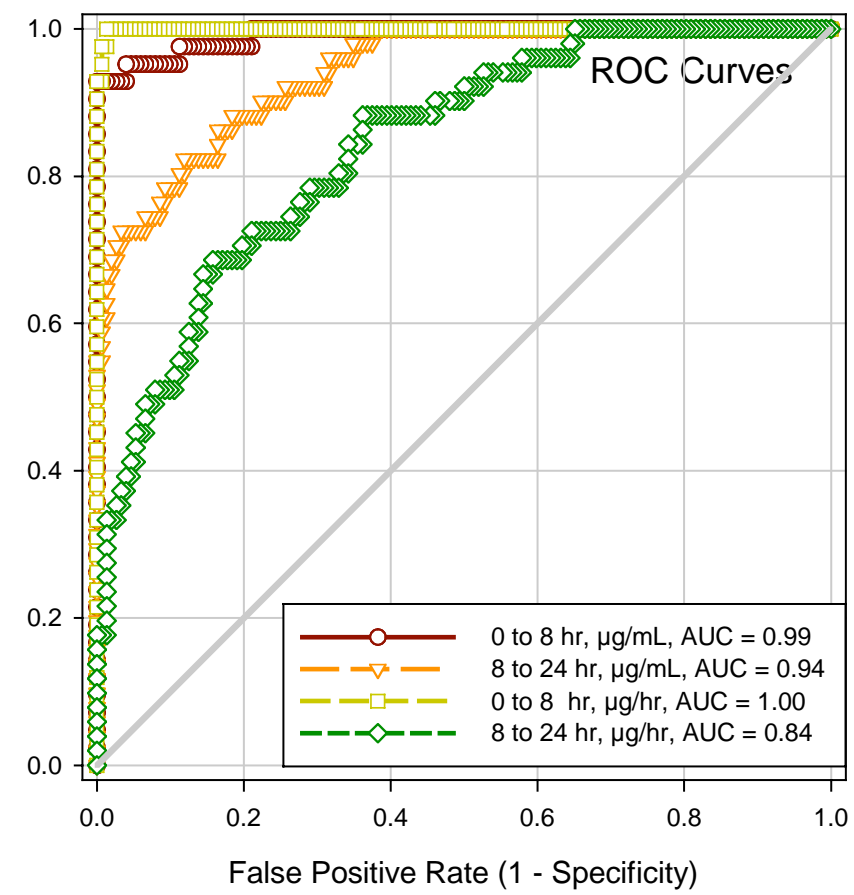

Fig. (2). Receiver operating characteristic (ROC) curves of urinary riboflavin as a tracer for medication compliance: comparison between different measures of urinary levels $(\mu \mathrm{g} / \mathrm{ml} \mathrm{vs.} \mu \mathrm{g} / \mathrm{hr})$ and between different intervals of pill ingestion to time of urine sampling (0-8 hrs vs. $8-24 \mathrm{hrs}$ ). AUC, area under the ROC curve.

\section{DISCUSSION}

Objective methods for rapidly assessing compliance can improve clinical trial management, conduct and interpretation of results. We studied the potential usefulness of assessing compliance by incorporating riboflavin at a dose of 32 $\mathrm{mg}$ /day into a study pill to be administered daily in a clinical study. The study pill was administered under controlled conditions to 6 healthy females whose intakes of supplements were restricted, and their urinary excretion of riboflavin was compared to that of 152 other women whose dietary and supplement intakes were not restricted. ROC curves indicated that riboflavin performed well as a compliance marker. In clinical studies, it is desirable to minimize both false positive rates (type I error, or misclassification of noncompliant subjects as compliant) and false negative rates (type II error, or misclassification of compliant subjects as noncompliant). With ingestion of a study pill containing $32 \mathrm{mg}$ of riboflavin, our results suggest that to keep type I error (misclassification of noncompliant subjects as compliant) below $5 \%$, a urinary riboflavin concentration of $>1.0 \mu \mathrm{g} / \mathrm{mL}$, or a substantial increase above baseline would indicate compliance with study pill ingestion.

The choice of a cut-off for compliance-membership classification may vary depending on the purpose (e.g. screening vs. diagnostic) of a clinical study and the intended study population (e.g. high risk or low risk). The desired balance of these factors may dictate whether the goal is to keep a low false positive rate or a low false negative rate if keeping both low is difficult. The pre-test probability of compliance or non-compliance is assumed to be 0.5 (as with the flip of a coin). At any chosen cut-off there will be a trade-off between false positive and false negative rates which under some cutoff values may be inversely related to each other. For clinical trials assessing drug efficacy, it is more important to keep the false positive rate (misclassification for those truly not taking the pill as taking the pills) low than to keep the false negative rate low (misclassification for those truly taking the pill as not taking the pills), because a high false positive rate is more likely to invalidate drug-efficacy study result and increase costs than will a higher false negative rate. For riboflavin, comparing levels before and after pill ingestion, in addition to considering a minimum cut-off of $>1.0 \mu \mathrm{g} / \mathrm{mL}$ will help keep the false negative rate low. Using both conditions for assessing compliance is likely to be stringent for many clinical studies, but should be tested in larger trials.

The $32 \mathrm{mg}$ of riboflavin provided in the study pill is near the upper limit of intestinal absorption of this vitamin [12], and was high enough to yield levels in urine sufficient for fluorescence measurement in previous clinical trials [10, 22]. The HPLC method we used for riboflavin is both sensitive and rapid. Riboflavin concentrations as low as $0.01 \mu \mathrm{g} / \mathrm{mL}$ can be measured within 30 minutes of collection of a urine sample, and the method is suitable for automation for rapid throughput analyses. Therefore, riboflavin, which can be incorporated into pills containing both an active substance and placebo, can serve as a marker for compliance that is measured independently of the active test substance. As shown in this study, urinary levels of riboflavin can be highly variable especially if nutritional supplements are not restricted, as in the group of 152 subjects. Riboflavin levels in these subjects were 2-4 times higher than in the 6 subjects 
in whom nutritional supplements were restricted (Table 2). In a clinical trial, it may be advisable to provide all study participants with standardized multi-vitamin supplementation and require that the participants avoid ingestion of their personal brand of vitamins. This study design may equalize background riboflavin exposure in all participants and enhance the efficacy of using riboflavin as a marker of compliance.

Additionally, the metabolism and disposition of active test substances, such as isoflavones, may be variable within a study population. The metabolism and disposition of the two isoflavones, daidzin and genistin contained in the study pill, have been studied extensively in our laboratory [15]. Daidzin and genistin are glycosides that undergo hydrolysis by intestinal flora, and their aglycones daidzein and genistein are then absorbed by the intestine, and metabolized in the liver to glucuronide and sulfate conjugates that are excreted in urine as such. The results of this study using a pill that contained all 3 substances indicate that riboflavin is a better marker for assessing compliance. Measurement of isoflavones is time consuming, first requiring hydrolysis of the glucuronides to the aglycones, followed by silylation and measurement by GC-FID [15], and is less suitable for rapid assessment of compliance. Moreover, we and others [23, 24] have found that these two isoflavones have widely different and variable urinary recoveries (Fig. 1B-C). In this study, there was better concordance between increases in riboflavin and daidzein excretion $(r=0.74)$ than between riboflavin and genistein excretion $(\mathrm{r}=0.59)$ in all six subjects who ingested the study pill. Therefore, either riboflavin or daidzein would be a better compliance marker than genistein for study pill ingestion.

The major strengths of this study are that urinary riboflavin and isoflavone excretions were studied for $24 \mathrm{hrs}$ after repeated ingestion of a pill containing riboflavin and two isoflavones, with multiple urine fractions collected at timed intervals. Moreover, the study pill was administered under controlled, supervised conditions to subjects with restricted vitamin supplement intakes, and riboflavin excretion was compared to subjects who did not take the pill and whose dietary and vitamin supplement intakes were not restricted. Measuring riboflavin concentration in spot urines collected at study site during a study that involves daily ingestion of a test pill is more desirable for monitoring compliance than collecting urine specimens at home. Cut-off levels of riboflavin excretion indicating compliance as defined under these conditions appear to be stringent, and need to be validated under other conditions for future large scale use in clinical trials.

In summary, an analytical method for measuring riboflavin in urine from women who ingested $32 \mathrm{mg}$ of riboflavin was found to be suitable for monitoring compliance in clinical studies and can be adapted for rapid throughput analysis. Results suggest that after a subject ingests $32 \mathrm{mg}$ of riboflavin, compliance is indicated by riboflavin levels in urine that are increased over an individual baseline or $\geq 1.0 \mu \mathrm{g} / \mathrm{mL}$. Measurement of urinary daidzein was also a reliable marker for compliance, but genistein was not. However, the assay for daidzein is much more time-consuming and less cost effective than that for riboflavin. ROC curves of riboflavin suggest that riboflavin in urine collected within $24 \mathrm{hrs}$ after pill ingestion is a useful marker for assessing compliance of daily pill ingestion.

\section{ACKNOWLEDGEMENTS}

The authors wish to acknowledge Neelam Bhopale for the analysis of riboflavin, the staff of the General Clinical Research Center for nursing and dietary support, and Dr. Brent Flickinger and the Archer Daniel Midland Co. for designing and providing riboflavin-isoflavone pills.

Research supported by National Institute of Health (NIH) R01 CA95545, NIH National Center for Research Resources General Clinical Research Center M01 RR00073 and 1UL1RR029876-01, NIH CA65628 and NIH 2 P30 ES06676. Clinical trial registration: Identifier NCT00204490 (www.ClinicalTrials.gov), registered on September 9, 2005.

\section{DISCLOSURES}

V.M. Sadagopa Ramanujam, K.E. Anderson, J.J. Grady, F. Nayeem, and L-J.W. Lu have no conflicts of interest.

\section{REFERENCES}

[1] Perel JM. Compliance during tricyclic antidepressant therapy: pharmacokinetic and analytical issues. Clin Chem 1988; 34(5): 881-7.

[2] Kastrissios H, Blaschke TF. Medication compliance as a feature in drug development. Annu Rev Pharmacol Toxicol 1997; 37: 451-75.

[3] Schoenen J, Jacquy J, Lenaerts M. Effectiveness of high-dose riboflavin in migraine prophylaxis. A randomized controlled trial. Neurology 1998; 50(2): 466-70.

[4] Riboflavin [vitamin B2] Available at: http: //www.mayoclinic.com/ health/vitamin-B2/NS_patient-riboflavin

[5] Thilothammal N, Krishnamurthy P, Banu K, Gandhimathy S. Testing compliance of drug taking--a simple bed side method. Indian Pediatr 1995; 32(3): 295-9.

[6] Anton R. New methodologies for pharmacological treatment trials for alcohol dependence. Alcohol Clin Exp Res 1996; 20(7 Suppl): 3A-9A.

[7] Del Boca F, Kranzler H, Brown J, Korner P. Assessment of medication compliance in alcoholics through UV light detection of a riboflavin tracer. Alcohol Clin Exp Res 1996; 20(8): 1412-7.

[8] Fuller R, Roth H, Long S. Compliance with disulfiram treatment of alcoholism. J Chronic Dis 1983; 36(2): 161-70.

[9] Fuller R, Branchey L, Brightwell D, et al. Disulfiram treatment of alcoholism. A Veterans Administration cooperative study. JAMA1986; 256(11): 1449-55.

[10] Switzer B, Stark A, Atwood J, Ritenbaugh C, Travis R, Wu H. Development of a urinary riboflavin adherence marker for a wheat bran fiber community intervention trial. Cancer Epidemiol Biomarkers Prev 1997; 6(6): 439-42.

[11] Baros A, Latham P, Moak D, Voronin K, Anton R. What role does measuring medication compliance play in evaluating the efficacy of naltrexone? Alcohol Clin Exp Res 2007; 31(4): 596-603.

[12] Ryu Y, Kim E, Song C. Riboflavin and thiamine absorption. Yonsei Med J 1968; 9(1): 11-3.

[13] Gatautis V, Naito H. Liquid-chromatographic determination of urinary riboflavin. Clin Chem 1981; 27(10): 1672-5.

[14] Chen M, Andrenyak D, Moody D, Foltz R. Determination of riboflavin by high-performance liquid chromatography with riboflavindepleted urine as calibration and control matrix. J Chromatogr B Analyt Technol Biomed Life Sci 2005; 820(1): 147-50.

[15] Lu L, Broemeling L, Marshall M, Ramanujam V. A simplified method to quantify isoflavones in commercial soybean diets and human urine after legume consumption. Cancer Epidemiol Biomarkers Prev 1995; 4(5): 497-503.

[16] Hanley J, McNeil B. The meaning and use of the area under a receiver operating characteristic [ROC] curve. Radiology 1982; 143(1): 29-36.

[17] Jusko WJ, Levy G. Absorption, protein binding, and elimination of riboflavin. Rivlin RS, Eds. New York: Plenum Press 1975.

[18] Levy G, Jusko W. Factors affecting the absorption of riboflavin in man. J Pharm Sci 1966; 55(3): 285-9. 
[19] Jusko W, Levy G. Absorption, metabolism, and excretion of riboflavin-5'-phosphate in man. J Pharm Sci 1967; 56(1): 58-62.

[20] Mayersohn M, Feldman S, Gibaldi M. Bile salt enhancement of riboflavin and flavin mononucleotide absorption in man. J Nutr 1969; 98(3): 288-96.

[21] Zempleni J, Galloway J, McCormick D. Pharmacokinetics of orally and intravenously administered riboflavin in healthy humans. Am J Clin Nutr 1996; 63(1): 54-66.
[22] Hobby GL, Deuschle KW. The use of riboflavin as an indicator of isoniazid ingestion in self-medicated patients. Am Rev Resp Dis 1959; 80: 415-23.

[23] Lu L, Grady J, Marshall M, Ramanujam V, Anderson K. Altered time course of urinary daidzein and genistein excretion during chronic soya diet in healthy male subjects. Nutr Cancer 1995; 24(3): 311-23.

[24] King R, Bursill D. Plasma and urinary kinetics of the isoflavones daidzein and genistein after a single soy meal in humans. Am J Clin Nutr 1998; 67(5): 867-72.

(C) Ramanujam et al.; Licensee Bentham Open.

This is an open access article licensed under the terms of the Creative Commons Attribution Non-Commercial License (http://creativecommons.org/licenses/by-nc/3.0/) which permits unrestricted, non-commercial use, distribution and reproduction in any medium, provided the work is properly cited. 